\title{
Color Features Based Flower Image Segmentation Using K-Means and Fuzzy C-Means
}

\author{
Perani Rosyani ${ }^{1, *}$, A Suhendi ${ }^{1}$, D H Apriyanti ${ }^{2}$, A A Waskita ${ }^{3}$ \\ ${ }^{1}$ Fakultas Tenik, Teknik Informatika, Universitas Pamulang, Tangerang Selatan, Indonesia \\ ${ }^{2}$ Purwodadi Botanic Garden, LIPI, Jawa Timur, Indonesia \\ ${ }^{3}$ Computer Network Subdivision, PPIKSN-BATANBuilding, Tangerang Selatan, Indonesia \\ Email: ${ }^{1}$ dosen00837@unpam.ac.id, ${ }^{2}$ dosen10007@unpam.ac.id, ${ }^{3}$ diah007@lipi.go.id, ${ }^{4}$ adhyaksa@batan.go.id \\ Email Penulis Korespondensi: dosen00837@unpam.ac.id \\ Submitted: 19/12/2021; Accepted: 27/12/2021; Published: 31/12/2021
}

\begin{abstract}
Abstrak-Investigasi lebih detail fitur warna untuk segmentasi bunga menggunakan K-means dan fuzzy C-means dilakukan dalam makalah ini. Gambar sampel yang berisi 1, 2, 3, 4 bunga dianthus deltoides L, yang diperoleh dari ImageCLEF 2017 akan digunakan. K-means dan fuzzy C-means akan menggunakan komponen model warna yang berbeda sebagai fitur untuk mengelompokkan objek bunga dari latar belakangnya sambil menjaga nilai k untuk K-means dan fuzzy C-means konstan. Kemudian kinerja dari pendekatan segmentasi tersebut akan dievaluasi dengan menggunakan informasi ground truth. Parameter evaluasi yang terlibat adalah jarak Hausdorff dan sejumlah metrik kinerja pengklasifikasi seperti akurasi, tingkat kesalahan, sensitivitas dan spesifisitas. Terlihat bahwa proses segmentasi akan sangat dipengaruhi oleh penggunaan komponen model warna lab.
\end{abstract}

\section{Kata Kunci: Segmentasi Citra Bunga; K-Means; Fuzzy C-Means; Fitur Warna; Analisis Blob; Hausdorff Distance}

Abstract-A more detail investigation of color feature for flower segmentation using K-means and fuzzy C-means was conducted in this paper. The sample images containing 1, 2, 3, 4 dianthus del- toides L flowers, obtained from ImageCLEF 2017 will be used. $\mathrm{K}$-means and fuzzy $\mathrm{C}$-means willuse different color model components as the feature for segmenting the flower objects from their background while keeping the value of $\mathrm{k}$ for K-means and fuzzy $\mathrm{C}$-means constant. Then the performance of the segmentation approaches will be evaluated by using the ground truth infor- mation. The evaluation parameters involved are Hausdorff distance and a number of classifier performance metrics such as accuracy, error rate, sensitivity and specivicity. It is shown that the segmentation process will greatly influenced by the use of LAB color model components.

Keywords: Flower Image Segmentation; K-Means; Fuzzy C-Means; Color Features; Blob Analysis; Hausdorff Distance

\section{PENDAHULUAN}

Segmentasi citra merupakan tahapan penting dalam pengolahan citra digital, baik untuk mendeteksi [1] maupun mengenali [2] suatu objek. Pengetahuan yang diperoleh dari fase ini berguna di beberapa bidang, misalnya di bidang pertanian. Lv et.al [3] mengembangkan metode segmentasi pada citra apel hijau dalam kantong menggunakan algoritma segmentasi Otsu. Pendekatan segmentasi ini didahului oleh peningkatan pemerataan histogram adaptif terbatas kontras dalam ruang warna RGB. Objek yang tersegmentasi kemudian dibandingkan dengan objek yang dihasilkan dengan pendekatan k-means clustering. Percobaan serupa dilakukan oleh Xiang [4] pada objek tomat berdasarkan gradien komentropi. Percobaan dilakukan dengan memvariasikan jenis pencahayaan, watt, angka, posisi, tata letak dan jarak ke objek. Alih-alih hanya menggunakan nilai intensitas, Xiang juga mempertimbangkan informasi spasial piksel. Kedua penelitian ini akan sangat meningkatkan manajemen pemanenan [5] dan teknik, misalnya dengan menggunakan robot pemanen [6] di bidang pertanian.

Selain mengenali spesies tertentu, laju pertumbuhan suatu tanaman dapat dipantau dari laju pertumbuhan daunnya [7]. Kemudian, kemampuan untuk mengekstrak daun dari citra sekitarnya dapat dimanfaatkan untuk merekam laju pertumbuhan suatu tanaman secara sering dan signifikan.

Selain buah-buahan, bagian lain dari pohon yang dapat digunakan sebagai ciri pengenal adalah daun [8] dan bunga $[9,10]$. Daun berbeda dari bunga karena karakteristik warnanya. Daunnya harus berwarna hijau, sedangkan bunganya sangat bervariasi. Ahli botani diuntungkan dengan menggunakan bagian itu untuk mengenali spesies tanaman dengan menggunakan karakteristik warna. Namun, penulis menggunakan model warna RGB saja.

Khusus untuk citra digital anggrek, Sabri et.al telah meneliti kinerja k-means dan fuzzy c-means (FCM) dengan menggunakan pendekatan berbasis wilayah [11]. Dalam pendekatan ini, area kebenaran dasar dibandingkan dengan area objek tersegmentasi untuk mengidentifikasi apakah terjadi segmentasi berlebih atau di bawah segmentasi. Penulis juga menggunakan False Positive Rate (FPR) dan False Negative Rate (FNR).

Alih-alih menggunakan model warna untuk mengenali bunga sebagai [2], model warna akan digunakan untuk mengelompokkan objek bunga dari latar belakangnya. Untuk mengevaluasi kinerja masing-masing pendekatan yang berbeda, analisis blob digunakan dalam makalah ini [12] berdasarkan fitur warna [13]. Jika pendekatan tertentu dapat menemukan sejumlah objek yang terdapat dalam sampel gambar, tingkat akurasi dan kesalahan dihitung berdasarkan batas objek yang tersegmentasi.

\section{METODOLOGI PENELITIAN}

\subsection{Tahapan Penelitian}


Berisi Dalam menyelidiki segmentasi berdasarkan fitur warna, metode berikut diusulkan seperti yang digambarkan pada Gambar. 1. Langkah pertama adalah membuat kebenaran dasar untuk setiap gambar sampel. Sampel gambar yang digunakan dalam makalah ini diperoleh dari ImageCLEF 2017 [14]. Sampel mengandung 1 (Gbr. 2 (a)), 2 (Gbr. 2(b)), 3 (Gbr. 2(c)) dan 4 (Gbr. 2(d)) bunga dianthus deltoides L. Gambar yang berisi 1 bunga dipangkas dari gambar yang berisi 2 bunga. Kebenaran dasar yang sesuai untuk setiap gambar sampel ditunjukkan pada Gambar. 3(a) - 3(d) masing-masing. Gambar kebenaran dasar ini dibuat dengan menggunakan pemilihan latar depan dari aplikasi GIMP [15]. Setelah itu, koordinat batas masing-masing objek pada Gambar 3(a) - 3(d) diidentifikasi. Pada tahap evaluasi, daftar koordinat batas ini akan dibandingkan dengan koordinat batas yang sesuai dari objek tersegmentasi untuk mengetahui akurasi segmentasi.

Langkah selanjutnya adalah melakukan segmentasi citra sampel, baik menggunakan k-means maupun FCM. Dalam mensegmentasi citra sampel, sejumlah model warna yang berbeda, termasuk RGB, HSV, LAB dan YCbCr digunakan. Setiap model warna memiliki komponen warna tersendiri yang digunakan sebagai pengenal karakter. Komponen warna yang digunakan dalam tulisan ini digabungkan secara berpasangan atau secara keseluruhan. Kemudian untuk model warna RGB, kita dapat menggunakan komponen warna sebagai pengenal karakter seperti RGB, RG, RB dan GB. Dengan menggunakan empat model warna yang berbeda, akan ada 16 pendekatan segmentasi yang masing-masing menggunakan K-means dan FCM.

Setelah melakukan segmentasi citra sampel, beberapa operator morfologi harus menerapkan hasil pengelompokan. Operator morfologi ini, termasuk pengisian lubang, operator median dan pembukaan, akan menghilangkan piksel-piksel yang bising

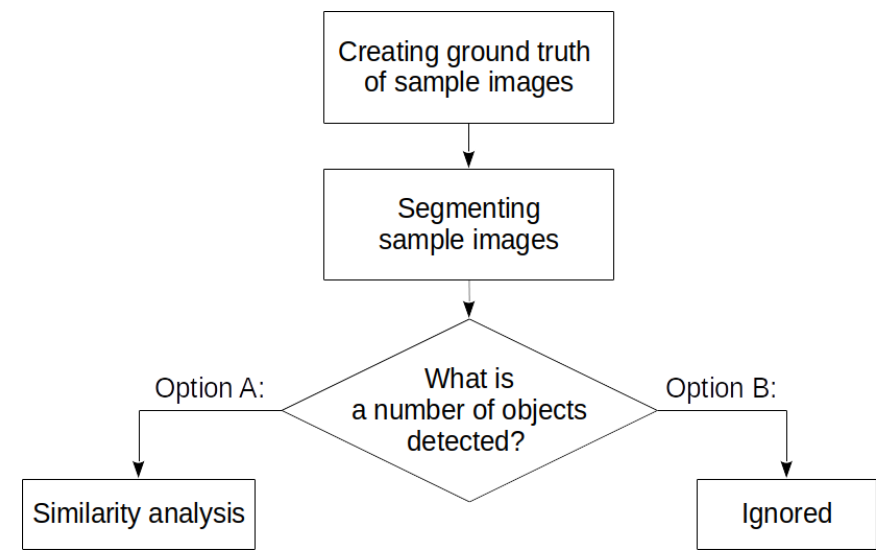

Gambar 1. Langkah-langkah dalam mengelompokkan objek bunga berdasarkan ciri warna
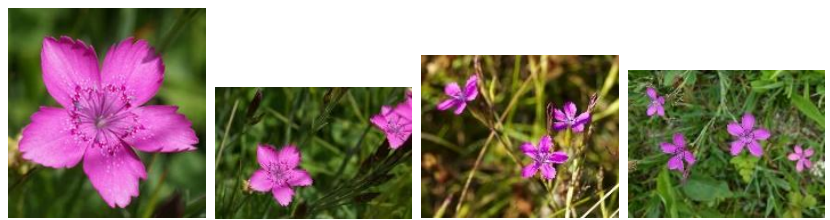

Gambar 2. Contoh gambar dianthus deltoides L flower

Dalam melakukan opsi A, beberapa pendekatan analisis kesamaan digunakan untuk mengevaluasi hasil segmentasi. Analisis pertama adalah jarak Hausdorff [16], yang akan diwakili oleh dH . dH dihitung dengan mencari jarak terpendek dari setiap titik di set pertama ke titik mana pun di set kedua. Di antara jarak terpendek sebelumnya, dH menemukan jarak maksimum. Menghitung dH dapat ditulis sebagai Persamaan. 1. Jarak Hausdorff ini telah diimplementasikan pada beberapa aplikasi clustering berbasis K-means seperti pada [17].

$$
d_{H}=\max _{x \in A} \min _{y \in B}\{\|x, y\|\}
$$

$\mathrm{dH}$ akan dihitung terhadap kebenaran dasar. Semakin rendah $\mathrm{dH}$ semakin mirip objek tersegmentasi yang diperoleh dengan kebenaran dasar. persamaan 1 menyiratkan bahwa kompleksitas dH adalah n2. Untuk setiap titik di A (kebenaran dasar), Persamaan. 1 akan menemukan jarak minimum ke titik manapun di B (objek tersegmentasi). Setiap jarak minimum yang diperoleh pada langkah pertama, nilai maksimum akan dipilih sebagai $\mathrm{dH}$.

Untuk menyesuaikan dengan hasil yang diperoleh sebelumnya, maka akan dihitung parameter akurasi dan error rate berdasarkan batas ground truth dan objek yang tersegmentasi. Akurasi dan tingkat kesalahan ini dapat dihitung dari matriks konfusi yang digambarkan pada Gambar 5. Batas digunakan sebagai dasar evaluasi untuk mencegah kesalahan arah dengan objek tersegmentasi yang memiliki luas total sama dengan kebenaran dasar tetapi bentuknya berbeda. 
TP (True Positive) mewakili titik-titik yang ada pada suatu kebenaran dasar dan juga ada pada objek yang tersegmentasi. Di sisi lain, FN (False Negative) mewakili titik-titik yang ada pada kebenaran dasar tetapi tidak ada pada objek yang tersegmentasi. Titik FN ini salah diklasifikasikan sebagai titik non-batas. Parameter selanjutnya adalah FP (False Positive). Ini mewakili titik-titik yang ada di batas objek tersegmentasi, tetapi tidak ada di kebenaran dasar. Terakhir, ada TN (True Negative) yang mewakili titik-titik yang tidak ada di ground truth dan sekaligus objek yang tersegmentasi. Akan tetapi, karena titik-titik yang terdapat dalam matriks konfusi hanya mewakili batas, maka titik yang termasuk dalam TN harus ditambah dengan titik yang bukan pada batas, yaitu titik-titik pada objek dan latar belakang. Karena menggunakan batas objek yang tersegmentasi, terjadi ketidakseimbangan data. Hal ini disebabkan jumlah titik yang membentuk batas suatu objek pasti jauh lebih sedikit dibandingkan dengan titik yang membentuk objek itu sendiri dan juga latar belakang. Kemudian, makalah ini juga mempertimbangkan untuk menghitung sensitivitas untuk mengevaluasi hasil.

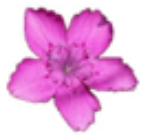

(a) 1 object

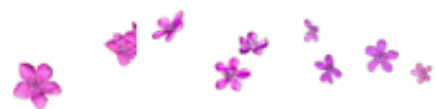

$\begin{array}{lll}\text { (b) } 2 \text { objects } & \text { (c) } 3 \text { objects } & \text { (d) } 4 \text { objects }\end{array}$

Gambar 3. Ground truth dari gambar bunga dianthus deltoides L

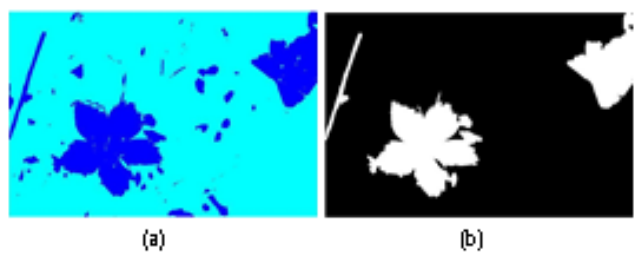

Gambar 4. Clustering dalam morphological transition when HSV color model were used and clustered based on $\mathrm{S}$ and $\mathrm{V}$ color components

Metrik evaluasi untuk pengklasifikasi yang digunakan dalam makalah ini adalah akurasi (didefinisikan dalam Persamaan 2), tingkat kesalahan (didefinisikan dalam Persamaan 3), sensitivitas (didefinisikan dalam Persamaan 4) dan spesifisitas (didefinisikan dalam Persamaan 5). Ukuran sampel citra masing-masing adalah $215 \times 229,600 \times 339$, 600x496 dan 600x450 untuk citra sampel yang berisi 1, 2, 3 dan 4 objek. Membandingkan ukuran gambar sampel dengan kebenaran dasar yang sesuai dapat diilustrasikan pada Gambar

$$
\begin{aligned}
& \text { Accuracy }=\frac{T P+T N}{p+N} \\
& \text { Error }=\frac{F P+F N}{P+N} \\
& \text { Sensitivity }=\frac{T P}{P} \\
& \text { Specificity }=\frac{T N}{N}
\end{aligned}
$$

\section{HASIL DAN PEMBAHASAN}

Dalam melakukan percobaan, penulis menggunakan nilai k sebesar 2 untuk FCM, sedangkan k sebesar 3 untuk Kmeans. Nilai ini diperoleh dari penelitian sebelumnya [2].

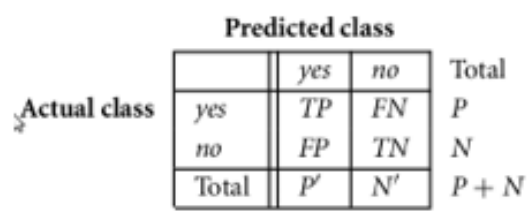

Gambar 5. Confusion Matrix [18]

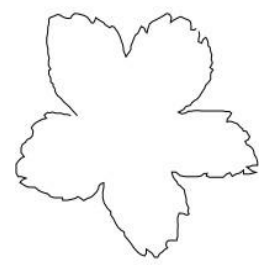

Gambar 6. Ground truth untuk contoh gambar yang berisi 1 objek bunga 
Hasil segmentasi yang berhasil mendeteksi jumlah objek pada citra sampel sebagai jumlah objek pada citra ground truth dicatat pada Tabel 1. Dari tabel tersebut, model warna konsisten yang berhasil mendeteksi objek bunga dengan benar menggunakan k-means dan FCM adalah model warna AB. Pada daftar kedua, terdapat komponen warna LAB dan HV yang hanya gagal dalam mensegmentasi citra sampel yang berisi 3 objek menggunakan FCM.

Berdasarkan pendekatan clustering, K-means berhasil melakukan segmentasi citra sampel yang berisi 2 objek bunga secara konsisten untuk setiap pilihan komponen warna. Di sisi lain, hasil serupa diperoleh dengan pendekatan FCM dalam mensegmentasi citra sampel yang berisi 1 objek bunga.

Tabel 1. Pilihan komponen model warna dan metode clustering yang berhasil mendeteksi objek bunga dengan benar

\begin{tabular}{ccccccccc}
\hline \multirow{2}{*}{ Color componen } & \multicolumn{9}{c}{ K-means } & \multicolumn{7}{c}{ FCM } \\
\hline RGB & 1 & 2 & 3 & 4 & 1 & 2 & 3 & 4 \\
RG & - & $\sqrt{ }$ & - & $\sqrt{ }$ & $\sqrt{ }$ & $\sqrt{ }$ & - & $\sqrt{ }$ \\
RB & $\sqrt{ }$ & $\sqrt{ }$ & - & - & $\sqrt{ }$ & - & - & - \\
GB & - & $\sqrt{ }$ & - & $\sqrt{ }$ & $\sqrt{ }$ & $\sqrt{ }$ & - & - \\
HS & - & $\sqrt{ }$ & $\sqrt{ }$ & $\sqrt{ }$ & $\sqrt{ }$ & $\sqrt{ }$ & - & - \\
HSV & & - & & $\sqrt{ }$ & & $\sqrt{ }$ & & $\sqrt{ }$ \\
HV & $\sqrt{ }$ & $\sqrt{ }$ & $\sqrt{ }$ & $\sqrt{ }$ & $\sqrt{ }$ & $\sqrt{ }$ & - & $\sqrt{ }$ \\
SV & - & $\sqrt{ }$ & - & - & $\sqrt{ }$ & - & - & - \\
LAB & $\sqrt{ }$ & $\sqrt{ }$ & $\sqrt{ }$ & $\sqrt{ }$ & $\sqrt{ }$ & $\sqrt{ }$ & - & $\sqrt{ }$ \\
LA & - & $\sqrt{ }$ & $\sqrt{ }$ & $\sqrt{ }$ & $\sqrt{ }$ & $\sqrt{ }$ & - & $\sqrt{ }$ \\
LB & - & $\sqrt{ }$ & $\sqrt{ }$ & $\sqrt{ }$ & $\sqrt{ }$ & $\sqrt{ }$ & - & $\sqrt{ }$ \\
AB & $\sqrt{ }$ & $\sqrt{ }$ & $\sqrt{ }$ & $\sqrt{ }$ & $\sqrt{ }$ & $\sqrt{ }$ & $\sqrt{ }$ & $\sqrt{ }$ \\
YCbCr & - & $\sqrt{ }$ & $\sqrt{ }$ & $\sqrt{ }$ & $\sqrt{ }$ & $\sqrt{ }$ & - & - \\
YCr & - & $\sqrt{ }$ & - & - & $\sqrt{ }$ & - & - & - \\
CbCr & $\sqrt{ }$ & $\sqrt{ }$ & - & $\sqrt{ }$ & $\sqrt{ }$ & $\sqrt{ }$ & - & $\sqrt{ }$ \\
\hline
\end{tabular}

Tabel 2 menyajikan dH menggunakan K-means dengan model warna RGB dan HSV, sedangkan Tabel 3 menyajikan dH yang sama dengan model warna LAB dan YCbCr. Karakter '-' pada tabel berarti dH tidak valid untuk dihitung karena banyaknya objek tersegmentasi yang tidak sama dengan ground truth masing-masing. Untuk FCM menggunakan model warna RGB dan HSV, hasilnya disajikan pada Tabel 4, sedangkan Tabel 5 untuk model warna LAB dan YCbCr.

Saat menggunakan K-means untuk segmentasi citra yang berisi 1 objek bunga, terdapat 5 pilihan komponen warna yang juga dapat mendeteksi 1 objek bunga. Masing-masing adalah komponen warna $\mathrm{AB}, \mathrm{HV}, \mathrm{CbCr}, \mathrm{LAB}$ dan RB. Namun parameter $\mathrm{dH}$ terbesar diperoleh dari komponen warna HV.

Tabel 2. dH untuk K-means dengan model warna RGB dan HSV

\begin{tabular}{ccccccccc}
\hline Color & \multicolumn{3}{c}{ RGB } & \multicolumn{5}{c}{ HSV } \\
\hline Components & RG & RB & GB & RGB & HS & HV & SV & HSV \\
1 flower & - & 29.0517 & - & - & - & 193.114 & - & - \\
2 flowers & 92.4662 & 95.2208 & 95.9896 & 95.0894 & 58.4380 & 58.4380 & 96.1145 & 58.4380 \\
3 flowers & - & - & - & - & 61.6279 & 61.6279 & - & 61.6279 \\
4 flowers & - & 128.5963 & 121.5895 & 126.5820 & 105.1332 & 108.9174 & - & 108.9174 \\
\hline
\end{tabular}

Tabel 3. dH untuk K-means dengan model warna LAB dan $\mathrm{YCbCr}$

\begin{tabular}{ccccccccc}
\hline \multicolumn{1}{c}{ Color } & \multicolumn{3}{c}{ LAB } & \multicolumn{3}{c}{ YCbCr } \\
\hline Components & LA & LB & AB & LAB & YCb & YCr & CbCr & YCbCr \\
1 flower & - & - & 27.037 & 22.8254 & - & - & 28.3901 & - \\
2 flowers & 61.8304 & 80.8826 & 67.8823 & 71.3512 & 96.9123 & 95.5196 & 71.1126 & 93.9894 \\
3 flowers & 105.5272 & 99.4032 & 84.4156 & 95.3362 & - & - & - & 112.3566 \\
4 flowers & 115.7886 & 115.447 & 120.7808 & 116.0302 & 126.5504 & - & 123.3086 & 119.5742 \\
\hline
\end{tabular}

Ini sama dengan 193.1140 (Tabel 2), sedangkan komponen warna lainnya menghasilkan dH kurang dari 30. Nilai ini sesuai dengan objek yang tersegmentasi seperti yang digambarkan pada Gambar 7. Gambar tersebut berbeda dari kebenaran dasarnya. Dalam makalah ini, penulis ingin mengevaluasi akurasi untuk kasus di mana semua komponen warna dapat dengan benar menyegmentasikan sejumlah objek seperti pada kebenaran dasar. Demikian halnya penggunaan K-means untuk citra sampel yang berisi 2 objek (Tabel 6 dan 7) dan penggunaan FCM untuk citra sampel yang berisi 1 objek (Tabel 8 dan 9). 


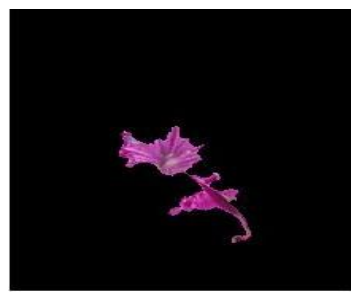

Gambar 7. Segmentasi objek menggunakan K-means dan komponen warna HV untuk citra yang mengandung 1 objek bunga

Dari Tabel 6 sampai 9, nilai akurasi hampir 1. Hal ini sangat dipengaruhi oleh jumlah titik yang menyusun objek dan latar belakang. Ini juga dikonfirmasi oleh parameter spesifisitas. Di sisi lain, parameter Sensitivitas berfluktuasi di antara penggunaan komponen model warna yang berbeda.

Nilai Sensitivitas lebih dari 0,5 dicapai bila segmentasi menggunakan komponen model warna LAB, termasuk variansnya, baik menggunakan K-means maupun FCM. Hal ini sejalan dengan fakta bahwa penggunaan komponen model warna $\mathrm{AB}$ dapat melakukan segmentasi objek pada suatu citra dengan benar. Sedangkan komponen model warna LAB mengikutinya. Nilai Sensitivitas tertinggi terjadi ketika K-means digunakan dengan komponen model warna LAB.

Tabel 4. Dn untuk FCM dengan model warna RGB dan HSV

\begin{tabular}{ccccccccc}
\hline \multicolumn{1}{c}{ Color } & \multicolumn{3}{c}{ RGB } & \multicolumn{4}{c}{ HSV } \\
\hline Components & RG & RB & GB & RGB & HS & HV & SV & HSV \\
1 flower & 32.8024 & 29.0517 & 35.3836 & 34.6554 & 24.7184 & 22.6716 & 34.1467 & 24.7184 \\
2 flowers & - & 85.8953 & 96.8710 & 90.6091 & 59.1523 & 59.1523 & - & 59.1523 \\
3 flowers & - & - & - & - & - & - & - & - \\
4 flowers & - & - & 114.3022 & 113.5958 & - & $106.4002-$ & - & \\
\hline
\end{tabular}

Tabel 5. Dn untuk FCM dengan model warna LAB dan $\mathrm{YCbCr}$

\begin{tabular}{ccccccccc}
\hline \multicolumn{1}{c}{ Color } & \multicolumn{3}{c}{ LAB } & \multicolumn{4}{c}{ YCbCr } \\
\hline Components & LA & LB & AB & LAB & YCb & YCr & CbCr & YCbCr \\
1 flower & 22.3607 & 27.4408 & 27.037 & 22.8254 & 38.2623 & 34.7994 & 28.3901 & 35.5246 \\
2 flowers & 67.9485 & 79.404 & 70.9507 & 70.6399 & - & - & 71.4983 & 92.6013 \\
3 flowers & - & - & 73.0958 & - & - & - & - & - \\
4 flowers & 111.9687 & 73.7631 & 112.5033 & 111.8079 & - & - & 117.4521 & - \\
\hline
\end{tabular}

Tabel 6. Metrik performa classifier untuk segmentasi citra bunga menggunakan K-means dengan model warna RGB dan HSV

\begin{tabular}{ccccccccc}
\hline Metrics & RGB & RG & RB & GB & HSV & HS & HV & SV \\
\hline TP & 377 & 452 & 335 & 380 & 806 & 800 & 805 & 374 \\
FN & 843 & 768 & 885 & 840 & 414 & 420 & 415 & 846 \\
FP & 890 & 915 & 922 & 875 & 454 & 460 & 455 & 993 \\
TN & 238134 & 238109 & 238123 & 238163 & 238449 & 238446 & 238449 & 238075 \\
Accuration & 0.9963 & 0.9965 & 0.9961 & 0.9964 & 0.9994 & 0.9994 & 0.9994 & 0.9960 \\
Error rate & 0.0072 & 0.0070 & 0.0075 & 0.0072 & 0.0036 & 0.0037 & 0.0036 & 0.0077 \\
Sensitivity & 0.3090 & 0.3705 & 0.2746 & 0.3115 & 0.6607 & 0.6557 & 0.6598 & 0.3066 \\
Specivicity & 0.9963 & 0.9962 & 0.9961 & 0.9963 & 0.9981 & 0.9981 & 0.9981 & 0.9958 \\
\hline
\end{tabular}

Tabel 7. Metrik kinerja pengklasifikasi untuk segmentasi citra bunga menggunakan K-means dengan model warna $\mathrm{LAB}$ dan $\mathrm{YCbCr}$

\begin{tabular}{ccccccccc}
\hline Metrics & LAB & LA & LB & AB & YCbCr & YCb & YCr & CbCr \\
\hline TP & 916 & 956 & 652 & 875 & 489 & 290 & 362 & 849 \\
FN & 304 & 264 & 568 & 345 & 731 & 930 & 858 & 371 \\
FP & 339 & 298 & 661 & 384 & 827 & 1027 & 958 & 406 \\
TN & 238459 & 238490 & 238315 & 238439 & 238203 & 238036 & 238075 & 238406 \\
Accuration & 0.9999 & 1.0002 & 0.9982 & 0.9996 & 0.9970 & 0.9955 & 0.9960 & 0.9994 \\
Error rate & 0.0027 & 0.0023 & 0.0051 & 0.0030 & 0.0065 & 0.0082 & 0.0076 & 0.0032 \\
Sensitivity & 0.7508 & 0.7836 & 0.5344 & 0.7172 & 0.4008 & 0.2377 & 0.2967 & 0.6959 \\
Specivicity & 0.9986 & 0.9988 & 0.9972 & 0.9984 & 0.9965 & 0.9957 & 0.9960 & 0.9983 \\
\hline
\end{tabular}


Building of Informatics, Technology and Science (BITS)

Volume 3, No 3, December 2021, Page 253-259

ISSN 2684-8910 (media cetak)

ISSN 2685-3310 (media online)

DOI 10.47065/bits.v3i3.1060

Tabel 8. Metrik kinerja pengklasifikasi untuk segmentasi gambar bunga menggunakan FCM dengan model warna RGB dan HSV

\begin{tabular}{ccccccccc}
\hline Metrics & RGB & RG & RB & GB & HSV & HS & HV & SV \\
\hline TP & 168 & 221 & 180 & 151 & 357 & 354 & 355 & 227 \\
FN & 537 & 484 & 525 & 554 & 348 & 351 & 350 & 478 \\
FP & 708 & 755 & 695 & 699 & 409 & 412 & 411 & 851 \\
TN & 47855 & 47823 & 47870 & 47866 & 48163 & 48160 & 48161 & 47717 \\
Accuration & 0.9754 & 0.9758 & 0.9759 & 0.9753 & 0.9855 & 0.9854 & 0.9854 & 0.9738 \\
Error rate & 0.0253 & 0.0252 & 0.0248 & 0.0254 & 0.0154 & 0.0155 & 0.0155 & 0.0270 \\
Sensitivity & 0.2383 & 0.3135 & 0.2553 & 0.2142 & 0.5064 & 0.5021 & 0.5035 & 0.3220 \\
Specivicity & 0.9854 & 0.9845 & 0.9857 & 0.9856 & 0.9916 & 0.9915 & 0.9915 & 0.9825 \\
\hline
\end{tabular}

Tabel 9. Metrik kinerja pengklasifikasi untuk segmentasi citra bunga menggunakan FCM dengan model warna LAB dan $\mathrm{YCbCr}$

\begin{tabular}{ccccccccc}
\hline Metrics & LAB & LA & LB & AB & YcbCr & Ycb & Ycr & $\mathrm{CbCr}$ \\
\hline TP & 436 & 429 & 305 & 430 & 357 & 139 & 182 & 386 \\
FN & 269 & 276 & 400 & 275 & 348 & 566 & 523 & 319 \\
FP & 329 & 343 & 524 & 331 & 409 & 855 & 887 & 379 \\
TN & 48228 & 48213 & 48036 & 48228 & 48163 & 47716 & 47683 & 48181 \\
Accuration & 0.9884 & 0.9880 & 0.9818 & 0.9883 & 0.9855 & 0.9720 & 0.9722 & 0.9864 \\
Error rate & 0.0121 & 0.0126 & 0.0188 & 0.0123 & 0.0154 & 0.0289 & 0.0286 & 0.0142 \\
Sensitivity & 0.6184 & 0.6085 & 0.4326 & 0.6099 & 0.5064 & 0.1972 & 0.2582 & 0.5475 \\
Specivicity & 0.9932 & 0.9929 & 0.9892 & 0.9932 & 0.9916 & 0.9824 & 0.9817 & 0.9922 \\
\hline
\end{tabular}

\section{KESIMPULAN}

Dari percobaan yang dilakukan, dapat disimpulkan bahwa penggunaan model warna yang berbeda sebagai fitur dalam segmentasi objek dalam citra digital akan mempengaruhi hasil. Dalam mensegmentasi objek bunga sejenis yang jumlahnya bervariasi dan berlatar belakang hijau, penggunaan komponen model warna LAB mencapai kinerja tertinggi di antara model lainnya seperti RGB, HSV dan YCbCr.

\section{REFERENCES}

[1] K. He, G. Gkioxari, P. Dollár, and R. B. Girshick, "Mask R-CNN," CoRR, vol. abs/1703.06870, 2017. [Online]. Available: http://arxiv.org/abs/1703.06870

[2] P. Rosyani, M. Taufik, A. A. Waskita, and D. H. Apriyanti, "Comparison of color model for flower recognition," in 2018 3rd International Conference on Information Technology, Infor- mation System and Electrical Engineering (ICITISEE), Nov 2018, pp. 10-14.

[3] J. Lv, F. Wang, L. Xu, Z. Ma, and B. Yang, "A segmentation method of bagged green apple image," Scientia Horticulturae, vol. 246, pp. $411-417, \quad 2019 . \quad$ [Online]. Available: http://www.sciencedirect.com/science/article/pii/S0304423818308112

[4] R. Xiang, "Image segmentation for whole tomato plant recognition at night," Computers and Electronics in Agriculture, vol. $154, \quad$ pp. $434 \quad 442, \quad 2018 . \quad$ [Online]. Available: http://www.sciencedirect.com/science/article/pii/S0168169918309268

[5] U.-O. Dorj, M. Lee, and S. seok Yun, "An yield estimation in citrus or-chards via fruit detection and counting using image processing," Computers and Electronics in Agriculture, vol. 140, pp. 103 - 112, 2017. [Online]. Available: http://www.sciencedirect.com/science/article/pii/S0168169916312455

[6] Y. Yu, K. Zhang, L. Yang, and D. Zhang, "Fruit detection for strawberry har- vesting robot in non-structural environment based on mask-rcnn," Computersand Electronics in Agriculture, vol. 163, p. 104846, 2019. [Online]. Available: http://www.sciencedirect.com/science/article/pii/S0168169919301103

[7] J. P. Kumar and S. Domnic, "Image based leaf segmentation and counting in rosette plants," Information Processing in Agriculture, vol. $\quad 6, \quad$ no. $\quad 2, \quad$ pp. $233 \quad-\quad 246, \quad 2019 . \quad$ [Online]. Available: http://www.sciencedirect.com/science/article/pii/S2214317318301562

[8] Z. Wang, K. Wang, F. Yang, S. Pan, and Y. Han, "Image segmentation of overlapping leaves based on chan-vese model and sobel operator," Information Processing in Agriculture, vol. 5, no. 1, pp. 1 - 10, 2018. [Online]. Available: http://www.sciencedirect.com/science/article/pii/S2214317317301270

[9] E. Zagrouba, S. B. Gamra, and A. Najjar, "Model-based graph-cut methodfor automatic flower segmentation with spatial constraints," Image and Vision Computing, vol. 32, no. 12, pp. 1007 - 1020, 2014. [Online]. Available: http://www.sciencedirect.com/science/article/pii/S0262885614001413

[10] S. Inthiyaz, B. Madhav, and P. Kishore, "Flower image segmentation with pca fused colored covariance and gabor texture features based level sets," Ain Shams Engineering Journal, vol. 9, no. 4, pp. 3277 - 3291, 2018. [Online]. Available: http://www.sciencedirect.com/science/article/pii/S2090447918300078

[11] N. Sabri, Z. Ibrahim, and N. N. Rosman, "K-means vs. fuzzy c-means for segmentationof orchid flowers," in $20167 \mathrm{th}$ 
IEEE Control and System Graduate Research Colloquium (ICSGRC), Aug 2016, pp. 82-86.

[12] W. Tan, T. Sunday, and Y. Tan, "Enhanced "grabcut" tool with blob analysis in segmentationof blooming flower images," in 2013 10th International Conference on Electrical Engineer- ing/Electronics, Computer, Telecommunications and Information Technology, May 2013, pp.1-4.

[13] K. Thorp and D. Dierig, "Color image segmentation approach to monitor flowering in lesquerella," Industrial Crops and Products, vol. 34, no. 1, pp. $1150 \quad-\quad 1159, \quad 2011 . \quad$ [Online]. Available: http://www.sciencedirect.com/science/article/pii/S0926669011001129

[14] “Imageclef / lifeclef - multimedia retrieval in clef," 2017. [Online]. Available: https://www.imageclef.org/2017

[15] "Gimp - gnu image manipulation program," accessed: August 20, 2019. [Online]. Available: https://www.gimp.org/

[16] A. A. Taha and A. Hanbury, "An efficient algorithm for calculating the exact hausdorff distance," IEEE Trans. Pattern Anal. Mach. Intell., vol. 37, no. 11, pp. 2153-2163, Nov. 2015. [Online]. Available: http://dx.doi.org/10.1109/TPAMI.2015.2408351

[17] J. Li, S. Tang, H. Zhang, Z. Li, W. Deng, C. Zhao, L. Fan, G. Wang, J. Liu, P. Yin, G. Xu, L. Zhang, and P. Tang, "Clustering of morphological fracture lines for identifying intertrochanteric fracture classification with hausdorff distance-based k- means approach," Injury, vol. 50, no. 4, pp. 939 - 949, 2019. [Online]. Available: http://www.sciencedirect.com/science/article/pii/S0020138319301329

[18] J. Han, M. Kamber, and J. Pei, "8 - classification: Basic concepts," in Data Mining (ThirdEdition), third edition ed., ser. The Morgan Kaufmann Series in Data Management Systems,

[19] J. Han, M. Kamber, and J. Pei, Eds. Boston: Morgan Kaufmann, 2012, pp. 327 - 391. [On- line]. Available: http://www.sciencedirect.com/science/article/pii/B9780123814791000083 